\title{
The effect of a physician-targeted intervention on metoclopramide prescribing practice
}

This article was published in the following Dove Press journal:

Therapeutics and Clinical Risk Management

22 August 201I

Number of times this article has been viewed

Yu-Xiao Yang ${ }^{1,2,3}$

Charles E Leonard ${ }^{2,3}$

Cristin Freeman ${ }^{2,3}$

Sean Hennessy ${ }^{2,3}$

'Division of Gastroenterology, ${ }^{2}$ Center for Clinical Epidemiology and Biostatistics, ${ }^{3}$ Department of Biostatistics and Epidemiology, University of Pennsylvania,

Philadelphia, PA, USA
Correspondence: Yu-Xiao Yang Center for Clinical Epidemiology and Biostatistics, University of Pennsylvania, 722 Blockley Hall, 423 Guardian Drive, Philadelphia, PA 19104-6021, USA

Tel +l 2 I5 5735027

Fax + I 2153495915

Email yangy@mail.med.upenn.edu
Background: Metoclopramide use is associated with serious and potentially irreversible neurologic side effects. However, it is often used for questionable or unclear indications in clinical practice.

Objectives: To (1) determine whether an intervention targeted at the prescribing physician would increase the rate of metoclopramide discontinuation among patients prescribed the medication for questionable or unclear indications; and (2) assess the durability of the discontinuation.

Study design: A randomized controlled trial.

Setting: Ambulatory practices of a quaternary care medical center.

Participants: Ambulatory, electronic medical record-utilizing clinicians of the quaternary medical center.

Intervention: A letter regarding participating clinicians' prescription(s) of metoclopramide for patients with questionable or unclear indications.

Main outcome measures: The rate and the durability of metoclopramide discontinuation.

Results: Fourteen of 31 (45\%) patients of intervention group clinicians and 10 of 30 (33\%) patients of nonintervention group clinicians had metoclopramide discontinued within 12 weeks, yielding a risk ratio for metoclopramide discontinuation of 1.4 (95\% confidence interval [CI] 0.6-3.0) in the intervention versus nonintervention group. Of the 29 patients who had their metoclopramide discontinued during the study, 26 (90\%, 95\% CI 73\%-98\%) still had no active metoclopramide prescription in the subsequent 6 months. No adverse events were detected during the follow-up period.

Conclusion: A physician-targeted intervention letter did not lead to a statistically significantly increased rate of metoclopramide discontinuation among patients who had questionable or unclear indications for the medication. Discontinuation of metoclopramide therapy for questionable or unclear indications was durable in most patients.

Keywords: metoclopramide therapy, EpicCare, prescription, discontinuation

\section{Introduction}

Metoclopramide is a 5-hydroxytryptamine (5-HT) $)_{4}$ agonist, dopaminergic, and 5- $\mathrm{HT}_{3}$ antagonist. It is commonly used as a pro-motility agent. The antidopamine receptor effect of metoclopramide can lead to extrapyramidal symptoms such as dystonia, akathisia, and tardive dyskinesia. ${ }^{1}$ Tardive dyskinesia is a potentially irreversible disfiguring movement disorder. Its prevalence among patients receiving chronic metoclopramide therapy has been reported to be as high as $29 \%{ }^{1}$ In fact, metoclopramide has been regarded by some to be the most common cause of tardive dyskinesia. ${ }^{2}$ Long-term treatment, increased cumulative dose, older age, and female sex are important risk 
factors for metoclopramide-induced tardive dyskinesia. ${ }^{2}$ In February 2009, the US Food and Drug Administration (FDA) required the manufacturers of metoclopramide to add a box warning about these risks and implement a risk evaluation and mitigation strategy. (http://www.fda.gov/newsevents/ newsroom/pressannouncements/ucm149533.htm.)

Furthermore, a recent analysis conducted by the FDA revealed that a substantial proportion of metoclopramide users are being prescribed the medication for longer than the 12-week maximum duration recommended by the drug label. ${ }^{3}$ Furthermore, many patients are receiving metoclopramide for unproven indications in practice. For example, a recent query of an outpatient electronic medical database system at our institution showed that from 1998 to 2003, use of metoclopramide had doubled, long-term use was prevalent, and over $33 \%$ of recipients were prescribed the medication for unspecified or questionable indications (gastritis, constipation, abdominal pain, or esophageal dysmotility) (unpublished data). In fact, $50 \%$ of prescriptions for questionable indications were for chronic therapy (ie, $\geq 12$ weeks). In addition, $17 \%$ of patients received metoclopramide for treatment of gastroesophageal reflux disease (GERD) in the absence of documented gastroparesis, a situation in which risk greatly outweighs benefit in the light of a proton pump inhibitor as a therapeutic alternative. Furthermore, a discussion of the potential side effects of metoclopramide was documented in the electronic charts of only $6 \%$ of persons on chronic metoclopramide therapy. These results suggest that a significant number of patients may be receiving chronic metoclopramide therapy with only an assumption of benefit, and therefore, may safely discontinue this potentially harmful medication.

Recent evidence suggests that a properly designed physician feedback intervention may be effective in changing physician prescribing practices. ${ }^{4}$ Essential elements of such a feedback should include: the identities of the inappropriately treated patients, detailed information regarding the prescription event in question, basis for the recommendations (ie, expert opinion, specific clinical evidence with references), and preservation of physician autonomy. ${ }^{4}$ Given the well known risk of tardive dyskinesia associated with metoclopramide and the high prevalence of potentially inappropriate prescribing of metoclopramide in our institution, we sought to evaluate whether a physician-targeted feedback intervention that included these essential elements resulted in more patients undergoing a trial of discontinuation of metoclopramide therapy. We also evaluated the long-term success rate (ie, durability) of this discontinuation trial.

\section{Methods}

\section{General study design}

The primary design of the study was a randomized controlled trial (ClinicalTrials.gov Identifier: NCT01126034) conducted at the prescribing physician level to assess the efficacy of a physician-targeted intervention, as determined by a patient's metoclopramide discontinuation within 6 weeks. Subsequently, clinicians initially assigned to receive no intervention were crossed-over to the intervention arm. Among all patients whose metoclopramide was discontinued, the durability of the discontinuation was assessed in a 6-month secondary follow-up period. The Institutional Review Board at the University of Pennsylvania approved the study along with waivers of informed consent and Health Insurance Portability and Accountability Act authorization.

\section{Data source}

Clinical Practices of the University of Pennsylvania (CPUP) are the physician-faculty practices of the University of Pennsylvania Health System, comprising approximately 725 primary care and specialty physicians, physician assistants, and advance practice nurses. EpicCare is the outpatient electronic medical record system used principally by CPUP practices. It captures all clinical notes for outpatient visits as well as phone calls and other orders that take place outside the context of a visit. Much of the detail of the note is recorded as unstructured text (ie, free text), though many important elements, such as diagnoses, prescription information, laboratory data, and radiology studies, are recorded as discrete, queriable fields. Additionally, EpicCare practitioners utilize this electronic medical record system to generate prescriptions. Therefore, it captures all medications ordered, along with dose instructions, dispense amount, and numbers of refills.

\section{Study population}

We included as potential study subjects all CPUP physicians, staff physician assistants, and staff certified registered nurse practitioners who prescribed medications and used EpicCare in their outpatient clinics as of March 2007. We excluded all physicians-in-training (ie, residents and fellows) and investigators of the current study.

\section{Randomization}

We first randomized all eligible CPUP physicians $(n=652)$ to either intervention or nonintervention status at a $1: 1$ ratio. The EpicCare database was then queried to identify all eligible physicians who were the ordering physician for at least one active prescription order for metoclopramide in 
EpicCare as of March 1, 2007. A prescription was considered active if the date of the last prescription before March 1, 2007 plus the intended duration of therapy of that prescription (including refills) was later than 30 days before March 1, 2007. Forty-four prescribers were identified, involving 85 physician-patient pairs. The EpicCare electronic medical records of all patients involved were then manually reviewed by a gastroenterologist (Y-X Y) to determine the indications for the metoclopramide prescriptions. The indications were determined by searching for the relevant diagnoses using International Classification of Diseases, Revision 9, codes and by manually reviewing clinician notes for all documented encounters. We defined questionable indications as: gastritis, constipation, abdominal pain, esophageal dysmotility, and GERD without documented gastroparesis. Patients who carried a diagnosis of gastroparesis or had a gastric emptying study documenting delayed gastric emptying were excluded from further analysis, as were pregnant patients who received metoclopramide for pregnancy related nausea and vomiting. Of the 652 eligible physicians randomized, only those who ordered an active metoclopramide prescription with a questionable indication $(n=38)$ eventually composed of the two comparison groups based on their original randomization assignment. The intervention group ultimately included 18 physicians and 31 patients; the nonintervention group included 20 physicians and 30 patients (Figure 1).

\section{Intervention}

Physicians in the intervention group were mailed a written feedback letter regarding their patients who were prescribed questionable metoclopramide therapy. Nonintervention providers received no letter. Since the randomization and intervention took place at the level of the ordering physicians, once a physician was assigned to the intervention group, he/she may have received multiple episodes of the intervention with reference to different patients if he/she prescribed metoclopramide with questionable indications for multiple patients. The letter consisted of the following components:

- The name and medical record number of the patient(s) involved

- Information regarding the metoclopramide prescription: dates, dosage, indication recorded, and the duration of therapy

- A reminder of the adverse effects of long-term metoclopramide therapy

- A recommendation to consider having the patient undergo a trial of metoclopramide discontinuation if appropriate, and chart documentation of a discussion of risk and benefits of metoclopramide therapy with patients

- A request that the physician document the discontinuation trial in the electronic medical record.

\section{Outcomes measured}

Twelve weeks after the intervention period, we searched the electronic medical records of patients in the intervention and nonintervention groups to determine whether discontinuation of metoclopramide therapy had taken place. Discontinuation status was defined as an EpicCare note documenting a trial of discontinuation based on record review (Y-X Y), or absence of any active metoclopramide prescription by the 84th day post-intervention (ie, 12 weeks).

\section{Administration of the intervention to the nonintervention group (crossover phase)}

Following the 12 weeks after the intervention letters were sent to the intervention group, the physicians in the nonintervention group who still had a patient on active metoclopramide therapy at that point were sent the same intervention letter. Another 12 weeks later, we searched the medical record to determine the rate of discontinuation of metoclopramide therapy among those who were in the original nonintervention group and received the intervention letter during the crossover stage.

\section{Assessment of durability of metoclopramide discontinuation}

For all patients whose metoclopramide was discontinued in either the initial phase or the crossover phase, their entire electronic medical records for the first 6 months following the discontinuation were manually reviewed by the gastroenterologist (Y-X Y) to determine whether they had an active prescription for metoclopramide during that period. A successful trial of metoclopramide discontinuation was defined as no prescription of metoclopramide during the 6 months following the initial discontinuation of therapy.

\section{Statistical analysis}

We used descriptive statistics to compare the characteristics of the providers and patients between the intervention and nonintervention groups. For the randomized controlled trial, comparison of the rates of patients entering a metoclopramide discontinuation trial between the intervention and nonintervention groups was performed. In order to account for clustering by physician, our primary analysis was performed using a generalized estimation equation (GEE) model to 


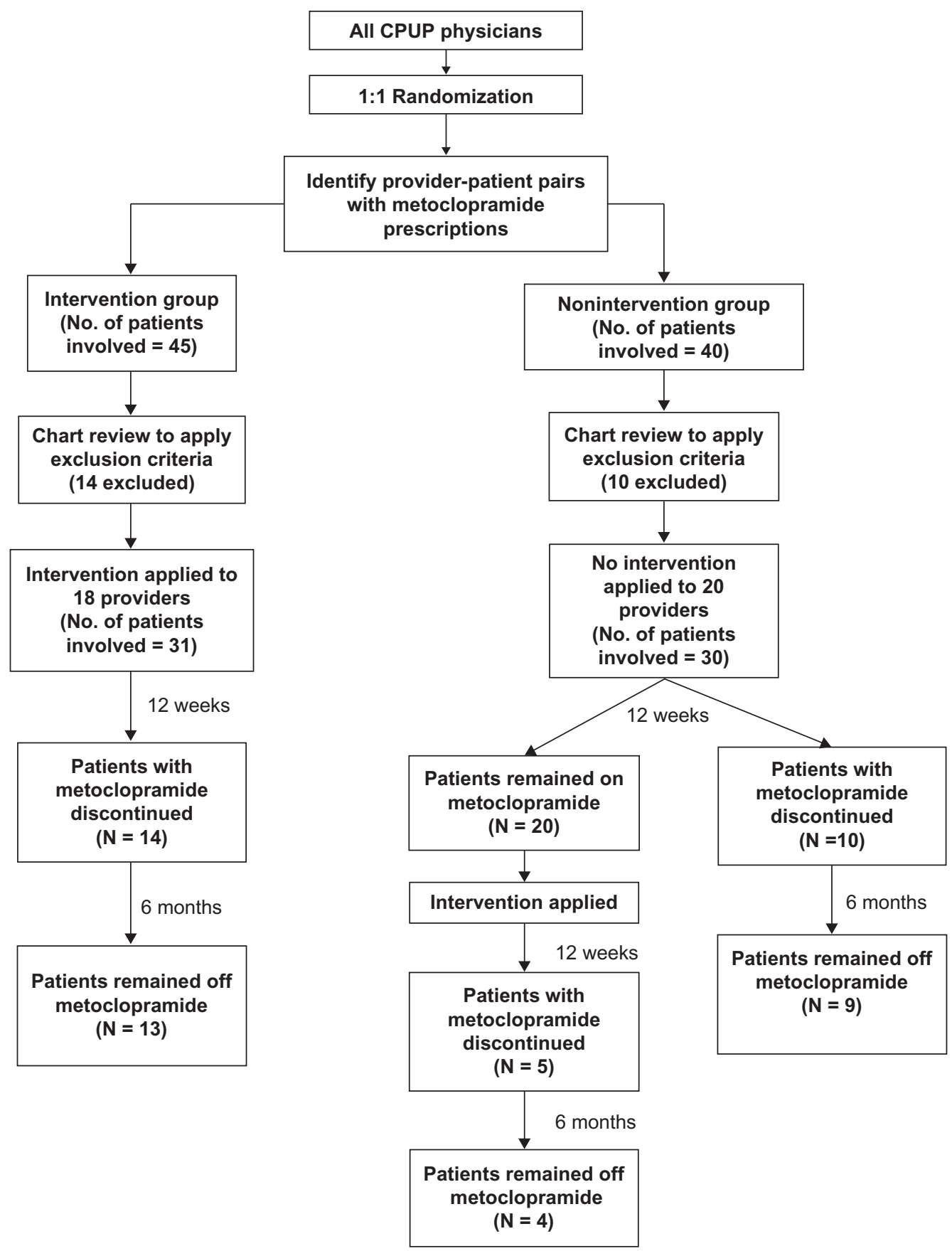

Figure I Study flow diagram.

estimate risk ratio. The rate and $95 \%$ confidence interval (CI) of 6-month persistent discontinuation were determined. All analyses were performed according to the intention-to-treat principle. Stata 8.0. (StataCorp LP, College Station, TX) was used for all analyses.

\section{Results}

The characteristics of the providers and patients in the intervention and nonintervention arms are compared in Table 1. Providers and patients in both arms were similar with respect to distribution of physician specialty, sex, age, and apparent indications for metoclopramide.

Among intervention group providers, 14 of 31 (45\%) patients had metoclopramide discontinued at 12 weeks post-intervention. In comparison, 10 of 30 (33\%) patients of nonintervention providers had metoclopramide discontinued at the same time point. The slightly higher rate of discontinuation in the intervention group did not meet the threshold for statistical significance. The risk ratio for metoclopramide discontinuation (ie, having no active metoclopramide 
Table I Comparisons of the providers and patients in the intervention and nonintervention groups ${ }^{\mathrm{a}}$

\begin{tabular}{|c|c|c|}
\hline & $\begin{array}{l}\text { Providers in } \\
\text { intervention } \\
\text { group } \\
(\mathrm{N}=18)\end{array}$ & $\begin{array}{l}\text { Providers in } \\
\text { nonintervention } \\
\text { group } \\
(\mathrm{N}=\mathbf{2 0})\end{array}$ \\
\hline \multicolumn{3}{|l|}{ Specialties } \\
\hline $\begin{array}{l}\text { General internal } \\
\text { medicine/primary care }\end{array}$ & 13 & 12 \\
\hline Nephrology & 2 & 2 \\
\hline Endocrine/diabetes clinic & 2 & 1 \\
\hline Gastroenterology & 0 & 2 \\
\hline Geriatrics & 1 & 1 \\
\hline Cardiology & 0 & 2 \\
\hline \multirow[t]{2}{*}{$\begin{array}{l}\text { Median number } \\
\text { of patients } \\
\text { per provider (range) }\end{array}$} & $I(I-8)$ & $I(I-3)$ \\
\hline & $\begin{array}{l}\text { Patients in } \\
\text { intervention } \\
\text { group } \\
(\mathbf{N}=3 \mathrm{I})\end{array}$ & $\begin{array}{l}\text { Patients in } \\
\text { nonintervention } \\
\text { group } \\
(\mathbf{N}=30)\end{array}$ \\
\hline Female sex & $20(65 \%)$ & $18(60 \%)$ \\
\hline $\begin{array}{l}\text { Mean age } \\
\text { (standard deviation) } \\
\text { Indication for } \\
\text { metoclopramide }\end{array}$ & $59(16)$ & $55(19)$ \\
\hline Unknown & 13 & 14 \\
\hline GERD & 14 & 12 \\
\hline Nausea/vomiting & 2 & 2 \\
\hline Epigastric pain & I & 1 \\
\hline Dysphagia & 1 & 0 \\
\hline
\end{tabular}

Note: $a p>0.05$ for all comparisons.

Abbreviation: GERD, gastroesophageal reflux disease.

prescription by the 12 -week time point) associated with receiving the intervention versus not receiving the intervention was 1.4 (95\% CI 0.6-3.0). Among the 24 patients who had metoclopramide therapy discontinued by the end of the randomized trial phase either spontaneously or following the intervention, 22 (92\%; 95\% CI 73\%-99\%) remained without an active metoclopramide prescription in the subsequent 6 months (Table 2).

Twenty of the 30 patients in the nonintervention group still had an active metoclopramide prescription at the end of the randomized trial phase (Table 3). According to our protocol, the physicians of all these 20 patients received the intervention letter at the end of the randomized trial phase. Of these, five (25\%) had metoclopramide discontinued 12 weeks after the intervention, and four of the five patients still had no active metoclopramide prescription after an additional 6 months of follow-up.

Overall, among the 29 metoclopramide users from either the intervention or nonintervention groups whose metoclopramide was discontinued during the entire study period, 26 (90\%; 95\% CI 73\%-98\%) still did not have an active metoclopramide prescription 6 months later. No adverse events as a result of the discontinuation were detected during the follow-up period among these patients based on electronic chart review.

\section{Discussion}

In this single-center randomized controlled trial, we found that a physician-targeted intervention letter led to a statistically nonsignificant increase in the rate of metoclopramide discontinuation among patients who had unspecified or questionable indications for metoclopramide. In addition, a metoclopramide discontinuation trial appeared safe and feasible in a large proportion of this selected population of metoclopramide users. Finally, the vast majority of those who enter the discontinuation trial remained off metoclopramide in the long term.

Metoclopramide can induce tardive dyskinesia, an irreversible movement disorder. Existing data suggest that the tardive dyskinesia mostly occur after prolonged exposure and high cumulative exposure. ${ }^{2}$ The metoclopramide drug label recommends against duration of therapy longer than 12 weeks, but off-label and long-term use of metoclopramide is prevalent in practice. ${ }^{3}$ In addition, there is no evidence to support the use of metoclopramide in gastritis, constipation, abdominal pain, or esophageal dysmotility. Furthermore, acid reflux disease can be managed with safer and more effective treatment alternatives in patients without documented

Table 2 Comparison of the intervention and nonintervention groups with regard to rate of metoclopramide discontinuation during the randomized trial and persistence of discontinuation

\begin{tabular}{|c|c|c|c|}
\hline & $\begin{array}{l}\text { Patients in } \\
\text { intervention arm } \\
(\mathbf{N}=31)\end{array}$ & $\begin{array}{l}\text { Patients in } \\
\text { nonintervention arm } \\
(\mathbf{N}=30)\end{array}$ & Risk ratio $(95 \% \mathrm{Cl})$ \\
\hline $\begin{array}{l}\text { Number of patients with metoclopramide } \\
\text { discontinued at the end of } 12 \text {-week randomized } \\
\text { trial (\%) }\end{array}$ & $14(45 \%)$ & $10(33 \%)$ & $1.4(0.6-3.0)$ \\
\hline $\begin{array}{l}\text { Number of patients remained off } \\
\text { metoclopramide during the next } 6 \text { months }\end{array}$ & 13 & 9 & NA \\
\hline
\end{tabular}

Abbreviations: $\mathrm{Cl}$, confidence interval; NA, not applicable. 
Table 3 Rate of metoclopramide discontinuation in the nonintervention arm during the crossover phase and persistence of discontinuation

Nonintervention group

$(\mathbf{N}=\mathbf{2 0})$

Number of patients with metoclopramide

$5(25 \%)$

discontinued 12 weeks after

their physician received intervention (\%)

Number of patients remained off

4

metoclopramide during the

next 6 months

delayed gastric emptying. Previous clinical trials have demonstrated the superiority of the proton pump inhibitors (PPIs) over metoclopramide monotherapy or metoclopramide in combination with a histamine 2 receptor antagonist in the treatment of GERD. ${ }^{5}$ In fact, because PPIs are such potent acid suppressants and highly effective in true GERD patients, most patients with persistent GERD-like symptoms not responding to PPI therapy likely have alternative explanations for their symptoms. In a minority of patients who truly have residual GERD symptoms after twice daily PPI therapy and evidence of delayed gastric emptying, a brief trial of metoclopramide therapy in addition to the PPI therapy might be considered. However, even this practice is not supported by conclusive evidence. Our results confirmed our suspicion that a significant proportion of patients with questionable indications for metoclopramide therapy can safely be taken off this medication, suggesting that they were not likely benefiting from the medication in the first place.

There are a wide range of interventions for improving physician practice. These mainly include auditing, feedbacks, reminders, opinion leaders, printed educational material, continuing medical education activities, educational outreach visits, patient mediated interventions, and local consensus processes. ${ }^{6}$ Many of these interventions have no effect based on large systematic reviews. ${ }^{7-10}$ Some of these methods such as auditing and feedback have shown some success, but none was effective in all situations. ${ }^{8,11}$ While a large systematic review concluded that physician feedback can improve physician practice, in particular prescribing, ${ }^{12}$ several previous randomized controlled studies found that an unsolicited written physician feedback system had a minimal effect on prescribing practices. ${ }^{4,13,14}$ Consistent with these data, our intervention letter, which contained all of the elements purported to be essential for effective physician feedback, ${ }^{4}$ also failed to lead to a statistically significant improvement in metoclopramide prescribing practices.
Our study has several important limitations. First the single-center nature limits its generalizability. Second, we may have been under-powered to detect a beneficial effect of the intervention letter. Third, our 6-month follow-up period may be too short to determine the long-term durability of the metoclopramide discontinuation. Fourth, there may be a potential clustering effect among physicians from the same practice (eg, they may be more likely to have similar prescribing habits), which might bias the results. However, we used GEE modeling in our analysis to account for this potential clustering effect. Finally, we used presence or absence of an active prescription in our medical records as a surrogate for actual metoclopramide use. This may have overestimated the rate of metoclopramide use among those who did not comply with the prescription. On the other hand, we might have underestimated metoclopramide use among patients who get their prescription from sources outside of our health system.

In summary, in this single-center randomized controlled trial, we revealed that a physician-targeted intervention letter to reduce inappropriate metoclopramide therapy might not be a very effective quality improvement intervention in a setting similar to ours. That being said, once patients receiving such therapy have it discontinued, they tend to remain off the drug at least over the next 6 months.

\section{Disclosure}

The authors report no conflicts of interest in this work.

\section{References}

1. Ganzini L, Casey DE, Hoffman WF, McCall AL. The prevalence of metoclopramide-induced tardive dyskinesia and acute extrapyramidal movement disorders. Arch Intern Med. 1993;153:1469-1475.

2. Pasricha PJ, Pehlivanov N, Sugumar A, Jankovic J. Drug insight: from disturbed motility to disordered movement - a review of the clinical benefits and medicolegal risks of metoclopramide. Nat Clin Pract Gastroenterol Hepatol. 2006;3:138-148.

3. Kaplan S, Staffa JA, Dal Pan GJ. Duration of therapy with metoclopramide: a prescription claims data study. Pharmacoepidemiol Drug Safety. 2007; 16:878-881.

4. Sondergaard J, Andersen M, Kragstrup J, Hansen P, Freng Gram L. Why has postal prescriber feedback no substantial impact on general practitioners' prescribing practice? A qualitative study. Eur J Clin Pharmacol. 2002;58:133-136.

5. Richter JE, Sabesin SM, Kogut DG, Kerr RM, Wruble LD, Collen MJ. Omeprazole versus ranitidine or ranitidine/metoclopramide in poorly responsive symptomatic gastroesophageal reflux disease. Am J Gastroenterol. 1996;91:1766-1772.

6. Thomson O'Brien MA, Oxman AD, Davis DA, Haynes RB, Freemantle N, Harvey EL. Audit and feedback versus alternative strategies: effects on professional practice and health care outcomes. Cochrane Database Syst Rev. 2000;(2):CD000260.

7. Thomson O'Brien MA, Oxman AD, Haynes RB, Davis DA, Freemantle N, Harvey EL. Local opinion leaders: effects on professional practice and health care outcomes. Cochrane Database Syst Rev. 2000;(2):CD000125. 
8. Oxman AD, Thomson MA, Davis DA, Haynes RB. No magic bullets: a systematic review of 102 trials of interventions to improve professional practice. CMAJ. 1995;153:1423-1431.

9. Davis DA, Thomson MA, Oxman AD, Haynes RB. Changing physician performance. A systematic review of the effect of continuing medical education strategies [see comment]. JAMA. 1995;274:700-705.

10. Freemantle N, Harvey EL, Wolf F, Grimshaw JM, Grilli R, Bero LA. Printed educational materials: effects on professional practice and health care outcomes. Cochrane Database Syst Rev. 2000;(2):CD000172.

11. Greco PJ, Eisenberg JM. Changing physicians' practices [see comment] New Engl J Med. 1993;329:1271-1273.
12. Thomson O'Brien MA, Oxman AD, Davis DA, Haynes RB, Freemantle N, Harvey EL. Audit and feedback: effects on professional practice and health care outcomes. Cochrane Database Syst Rev. 2000;(2):CD000259. Update in Cochrane Database Syst Rev. 2003;(3):CD000259.

13. Sondergaard J, Andersen M, Stovring H, Kragstrup J. Mailed prescriber feedback in addition to a clinical guideline has no impact: a randomised, controlled trial. Scand J Prim Health Care. 2003;21:47-51.

14. O'Connell DL, Henry D, Tomlins R. Randomised controlled trial of effect of feedback on general practitioners' prescribing in Australia. BMJ. 1999;318:507-511.

\section{Publish your work in this journal}

Therapeutics and Clinical Risk Management is an international, peerreviewed journal of clinical therapeutics and risk management, focusing on concise rapid reporting of clinical studies in all therapeutic areas, outcomes, safety, and programs for the effective, safe, and sustained use of medicines. This journal is indexed on PubMed Central, CAS,

Submit your manuscript here: http://www.dovepress.com/therapeutics-and-clinical-risk-management-journal
EMBase, Scopus and the Elsevier Bibliographic databases. The manuscript management system is completely online and includes a very quick and fair peer-review system, which is all easy to use. Visit http://www.dovepress.com/testimonials.php to read real quotes from published authors. 